\title{
Layered Extraction and Adsorption Performance of Extracellular Polymeric Substances from Activated Sludge in the Enhanced Biological Phosphorus Removal Process
}

\author{
Daxue $\mathrm{Li}^{1,2}$ and Hailing $\mathrm{Xi}^{1, *(1)}$ \\ 1 State Key Laboratory of NBC Protection for Civilian, Beijing 102205, China; lidaxue678@163.com \\ 2 Department of Military Installations, Army Logistic University of PLA, Chongqing 401331, China \\ * Correspondence: fhyjyxihl@163.com; Tel.: +86-10-66758299
}

Received: 1 September 2019; Accepted: 12 September 2019; Published: 16 September 2019

\begin{abstract}
A large amount of phosphorus was found in the extracellular polymeric substances (EPS) of activated sludge used in enhanced biological phosphorus removal (EBPR), so the role of EPS and extracellular phosphorus in EBPR should not be neglected. The composition and properties of tightly bound EPS (TB-EPS) and loosely bound EPS (LB-EPS) were significantly different, and it was necessary to study the adsorption performance of EPS through the fractionating of activated sludge into LB-EPS, TB-EPS and microbial cells. In this study, the adsorption performance of LB-EPS and TB-EPS for phosphate was explored by extracting LB-EPS and TB-EPS via sonication and cation exchange resin (CER), respectively. The results indicated that the sonication-CER method was an efficient and reliable extraction method for EPS with a synergistic effect. The performance of EPS in the adsorption/complexing of phosphate was excellent because of its abundant functional groups. Specifically, the type and content of metal elements and functional groups in TB-EPS were much greater than those in LB-EPS, which led to the key role of TB-EPS in the adsorption/complexing of phosphate. Finally, a metabolic model for EBPR with consideration of the adsorption performance of LB-EPS and TB-EPS was proposed.
\end{abstract}

Keywords: enhanced biological phosphorus removal (EBPR); tightly bound extracellular polymeric substances (TB-EPS); loosely bound extracellular polymeric substances (LB-EPS); phosphate; adsorption performance

\section{Introduction}

Extracellular polymeric substances (EPS) are widely distributed in biological aggregates, which has an important influence on the wastewater biological treatment process [1,2]. In the past two decades, EPS have been shown to contain a large amount of phosphorus, which is the phosphorus storage and transfer station in the enhanced biological phosphorus removal (EBPR) process [3]. Importantly, the role of EPS in the EBPR process is nonnegligible and should be considered in the mechanisms of phosphorus removal. In activated sludge, microbial cells are embedded within EPS, which can be divided into tightly bound EPS (TB-EPS) located in the inner layer of the sludge floc and loosely bound EPS (LB-EPS) existing in the outer layer of the sludge floc [1,4]. The contents, compositions and properties of TB-EPS and LB-EPS were found to be different [5-7], and their influences on the flocculation, sedimentation and dewatering of activated sludge were also significantly different. To acquire more information about the exact role of EPS in EBPR, it is necessary to fractionate EPS into TB-EPS and LB-EPS. 
There are many methods to extract EPS from EBPR sludge, including sonication, cation exchange resin (CER), sonication-CER, heating, alkali treatment, ethylenediaminetetraacetic acid (EDTA), and formaldehyde/ $\mathrm{NaOH}$ treatment $[8,9]$. In recent years, the sonication method has been gradually favored by researchers. However, the biggest limitation of sonication for extracting EPS is a low extraction efficiency, but the sonication-CER method can solve this problem $[4,10,11]$. The content and species of extracellular phosphorus are seldom affected by intracellular phosphorus in the extraction process with CER or sonication [9], which is the basis of accurate analysis of extracellular phosphorus. The phosphorus content of EPS can reflect the role of EPS in biological phosphorus removal. Zhang et al. [3] compared the formaldehyde- $\mathrm{NaOH}$ extraction method with sonication, EDTA, heating and CER extraction, and the results showed that CER extraction was more suitable for extracting EPS from EBPR sludge. Moreover, although the formaldehyde- $\mathrm{NaOH}$, EDTA and heating extractions had higher EPS extraction efficiencies, these methods caused chemical pollution and bacterial cell lysis. Therefore, the extraction of extracellular polymers from EBPR sludge by sonication and CER is an effective way to study the adsorption ability.

EPS are a kind of macromolecular mixture produced by microorganisms under specific conditions, the components of which are mainly proteins, humus and polysaccharides [8]. Due to the existence of these macromolecular substances, EPS have a large surface area and many functional groups, including carboxyl, phosphate, sulfate, amino, phenol, hydroxyl and other active groups [12]. Many functional groups in EPS can adsorb heavy metals by electrostatic interactions or complexation. In addition, hydrophobic regions exist in EPS, which can adsorb nonpolar organic pollutants. With the above characteristics, the adsorption capacity for heavy metals and organic pollutants in wastewater is strong $[13,14]$. The interaction between phosphorus and EPS is beneficial for the accumulation of polyphosphate (polyP) in EPS. The content of extracellular phosphorus can reach nearly $10 \%$ of total phosphorus in EBPR-activated sludge [2]. Biological phosphorus removal from wastewater is mainly achieved by discharging phosphorus-rich activated sludge, so the combination of EPS and phosphorus will not only affect phosphorus absorption and utilization but also affect phosphorus removal in EBPR bioreactors [15].

In biological treatment systems, the type of organic substrate and temperature that have substantial effects on the microbial community and metabolism are important factors in biological phosphorus removal [16-18]. Acetate and propionate are the typical volatile fatty acids (VFAs) in sewage or municipal wastewater, which are key carbon sources for the EBPR process $[19,20]$. Temperatures higher than $20^{\circ} \mathrm{C}$ were generally reported as unfavorable to the EBPR process, so the EBPR technique might not be suitable for tropical climates with temperatures above $30^{\circ} \mathrm{C}$ [21-24]. Furthermore, the content and composition of LB-EPS and TB-EPS as well as their roles in biological phosphorus removal might also be influenced by the type of organic substrate and the temperature. However, information about the role of LB-EPS and TB-EPS in phosphate adsorption/complexing under different temperatures and substrate types has not been presented in the literature. This study aimed to investigate the roles of LB-EPS and TB-EPS in EBPR. For this purpose, four lab-scale Anacrobic/Oxic Sequencing Batch Reactor (A/O-SBR) reactors with different temperatures $\left(20 \pm 1{ }^{\circ} \mathrm{C}\right.$ or $35 \pm 1{ }^{\circ} \mathrm{C}$ ) and organic substrates (acetate or propionate) were operated under steady-state conditions. LB-EPS and TB-EPS were extracted by the sonication method and the CER method, respectively, and the contents and functional groups in sludge flocs were analyzed. The differences in adsorption performance between LB-EPS and TB-EPS were evaluated. Furthermore, the biochemical reaction process of TB-EPS phosphate adsorption/complexing in activated sludge was clarified to understand the roles of LB-EPS and TB-EPS in EBPR.

\section{Results and Discussion}

\subsection{Extraction Efficacy of EPS}

The extraction efficacy of EPS via sonication-CER was better than that with sonication or CER alone. From Figure 1, the extraction amounts of EPS with sonication, CER, and sonication-CER 
were 11.75 28.06 mg total organic carbon (TOC)/g volatile suspended solid (VSS), 36.64 138.15 mg TOC/g VSS, and 51.26 168.27 mg TOC/g VSS, respectively, which were equivalent to $2.9 \% \sim 6.4 \%$, $8.9 \% \sim 31.5 \%$, and $12.4 \% \sim 38.4 \%$ of $\mathrm{TOC}_{\text {sludge, }}$, respectively. For the four kinds of activated sludge, the amount of EPS extracted via sonication-CER was greater than the sum of that extracted with sonication and CER individually, which suggested that there was a synergistic effect when extracting EPS via sonication-CER.
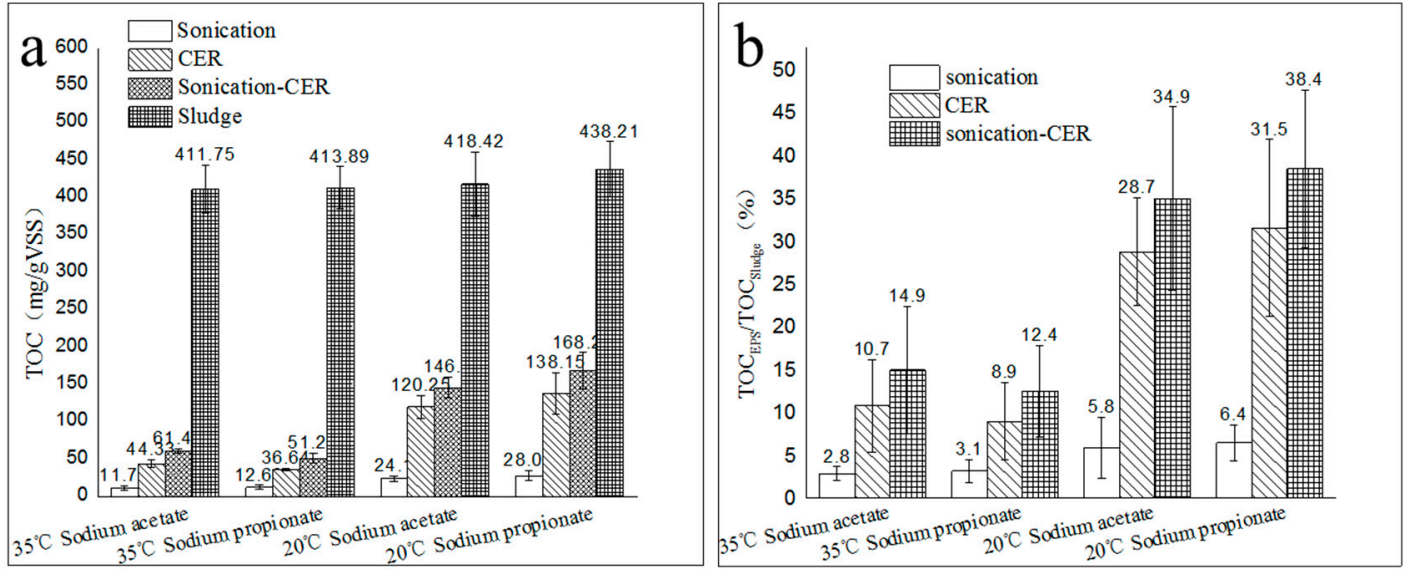

Figure 1. The extracted amounts of extracellular polymeric substances (EPS) when utilizing sonication, cation exchange resin (CER), and sonication-CER. (a): $\mathrm{TOC}_{\mathrm{EPS}}$ and $\mathrm{TOC}_{\text {sludge; }}$ (b): $\mathrm{TOC}_{\mathrm{EPS}} / \mathrm{TOC}_{\text {sludge }}$ ratio. Abbreviations: TOC: total organic carbon; VSS: volatile suspended solid.

As shown in Figure 2, the amount of TB-EPS extracted from activated sludge was much higher than that of LB-EPS, mainly because TB-EPS was a dense layer close to the outside of the microbial cell membrane and contained protein molecules with higher molecular weight. The content of LB-EPS and TB-EPS in activated sludge with sodium acetate or sodium propionate as the sole carbon source at $20^{\circ} \mathrm{C}$ was greater than that at $35^{\circ} \mathrm{C}$, indicating that the net production of LB-EPS and TB-EPS in activated sludge at high temperature $\left(35^{\circ} \mathrm{C}\right)$ was lower. Furthermore, the changes in the TB-EPS content of activated sludge at $20^{\circ} \mathrm{C}$ were less than those at $35^{\circ} \mathrm{C}$ during the anaerobic-aerobic cycle, indicating that the inner structure of the activated sludge cultured at $20^{\circ} \mathrm{C}$ was more stable.

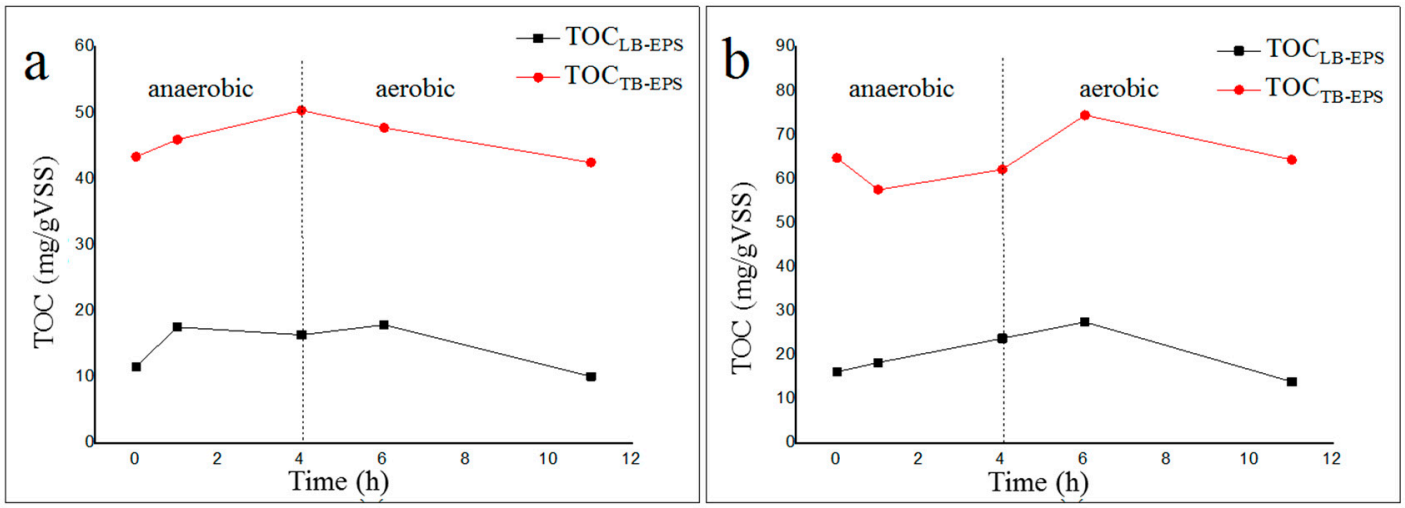

Figure 2. Cont. 

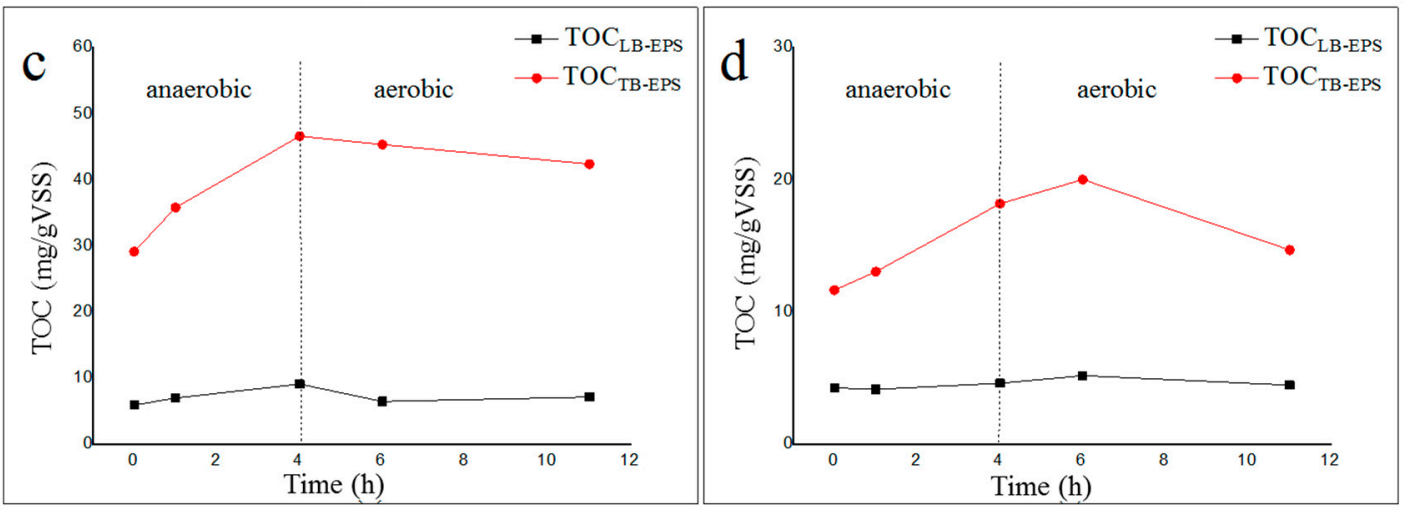

Figure 2. Content of loosely bound extracellular polymeric substances (LB-EPS) and tightly bound extracellular polymeric substances (TB-EPS) during the anaerobic-aerobic cycle. (a): LB-EPS and TB-EPS from a $20^{\circ} \mathrm{C}$ sodium acetate reactor; (b): LB-EPS and TB-EPS from a $20^{\circ} \mathrm{C}$ sodium propionate reactor; (c): LB-EPS and TB-EPS from a $35^{\circ} \mathrm{C}$ sodium acetate reactor; (d): LB-EPS and TB-EPS from a $35{ }^{\circ} \mathrm{C}$ sodium propionate reactor.

\subsection{Phosphorus Removal Performance and Microbial Ecological Mechanism}

The biological phosphorus removal performances of the 4 A/O-SBR reactors were distinctly different (Figure 3). From Figure 3, the profiles of total phosphorus (TP) in the supernatant of the $20{ }^{\circ} \mathrm{C}$ reactors presented a typical EBPR pattern, with a considerable transportation of TP from the sludge to the bulk solution in the anaerobic period and an opposite flow in the aerobic period. Nevertheless, the activated sludge in the $35^{\circ} \mathrm{C}$ reactors had non-EBPR performance, with a relatively stable value of TP in solution during the anaerobic-aerobic cycle. The above results show that temperature has an important influence on the biological phosphorus removal performance of activated sludge, which is consistent with the work published by Kee et al. [21] and Sayi et al. [22]. Phosphorus-accumulating organisms (PAOs) are the key functional microorganisms in EBPR and play an important role in biological phosphorus removal [25]. According to the microscope images acquired with scanning electron microscopy (SEM) (see Figure 4), the main microorganisms in the sludge of the two $20^{\circ} \mathrm{C}$ reactors were rod-shaped bacteria, which are common PAOs and play a major role in EBPR. Nevertheless, the main microorganisms in the sludge of the two $35^{\circ} \mathrm{C}$ reactors were filamentous bacteria, which had poor phosphorus removal performance, and sludge bulking occurred under deteriorating environmental conditions, which caused the irreversible collapse of the reactor.

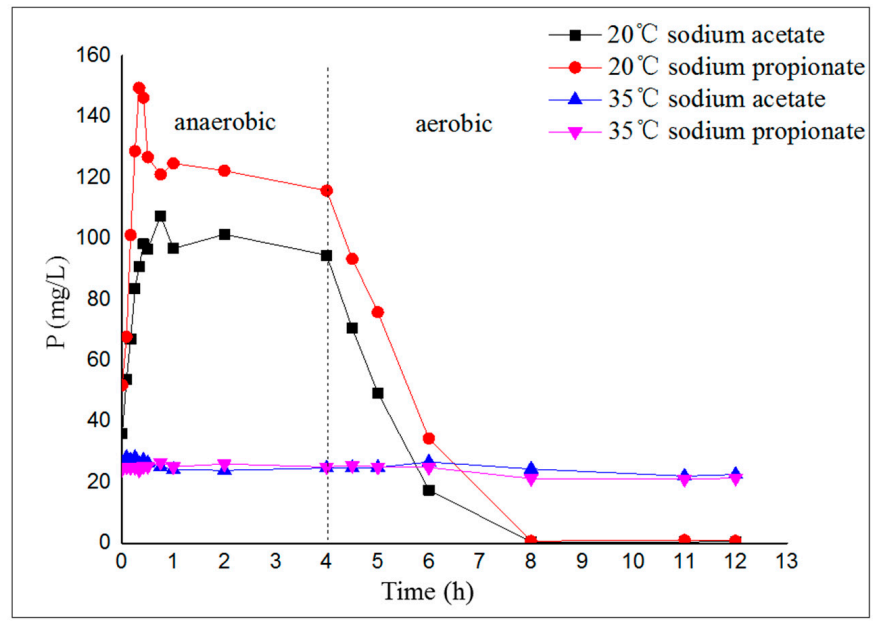

Figure 3. The variation of total phosphorus (TP) concentration in the supernatant during the anaerobic-aerobic cycle. 

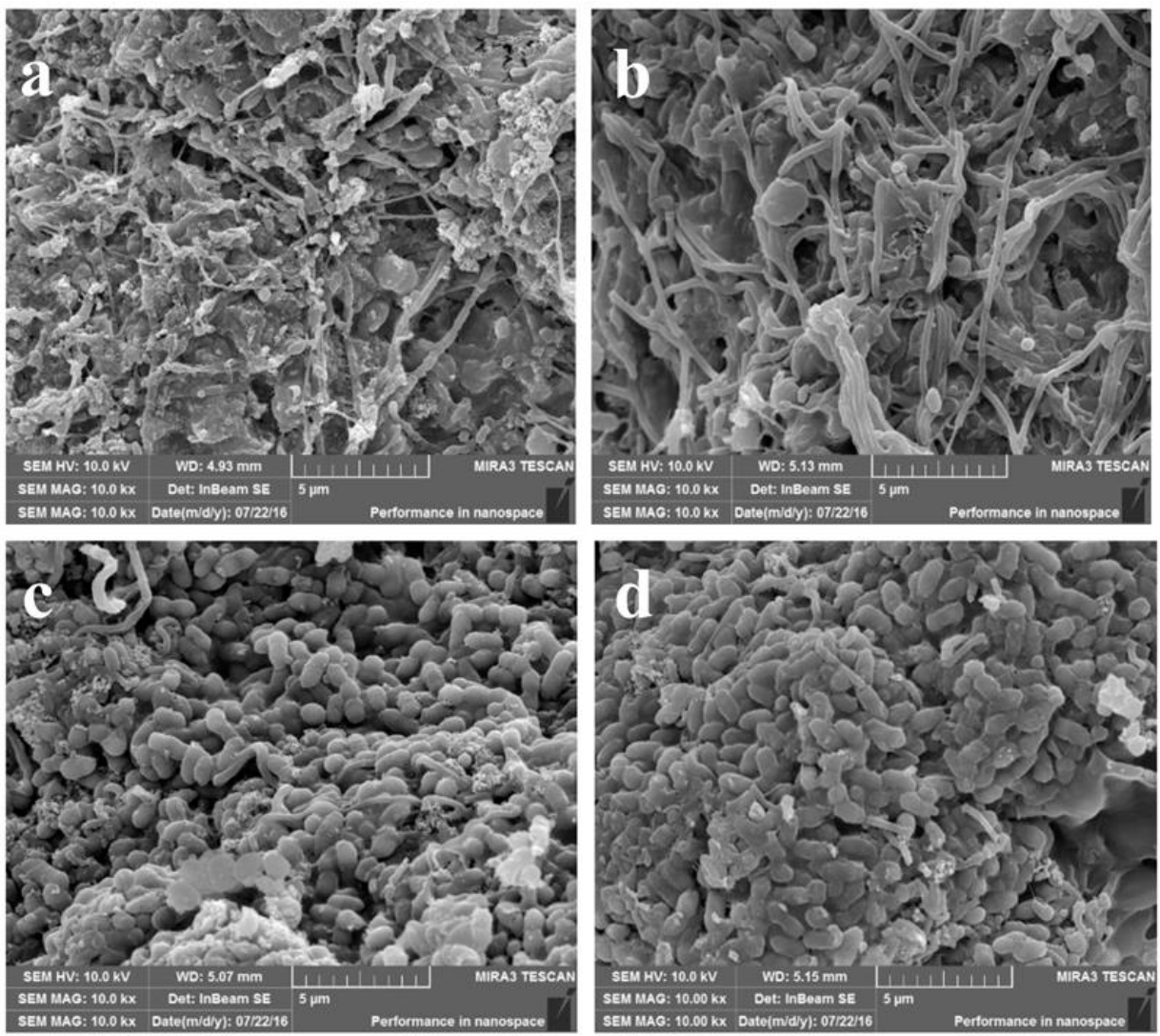

Figure 4. Microbial morphology of the four reactors observed by SEM. (a): Microbial morphology of a $35{ }^{\circ} \mathrm{C}$ sodium acetate reactor; (b): microbial morphology of a $35{ }^{\circ} \mathrm{C}$ sodium propionate reactor; (c): microbial morphology of a $20{ }^{\circ} \mathrm{C}$ sodium acetate reactor; (d): microbial morphology of a $20{ }^{\circ} \mathrm{C}$ sodium propionate reactor.

\subsection{Properties of LB-EPS and TB-EPS Phosphorous Adsorption/Complexing}

As shown in Figure 5, the Fourier-transform infrared spectroscopy (FTIR) spectra of EPS in activated sludge of the two $35{ }^{\circ} \mathrm{C}$ reactors and the two $20{ }^{\circ} \mathrm{C}$ reactors were extremely different, indicating that the biochemical reaction temperature affected the type and content of functional groups of LB-EPS and TB-EPS. The difference in infrared spectra between LB-EPS and TB-EPS in the $35^{\circ} \mathrm{C}$ reactors was mainly concentrated in the fingerprint region $\left(<1000 \mathrm{~cm}^{-1}\right)$, which indicated that there were significant differences in the amount of phosphorous-containing and sulfur-containing groups between LB-EPS and TB-EPS in activated sludge. The position and amount of absorption peaks in the functional group region (1000-2500 $\left.\mathrm{cm}^{-1}\right)$ of LB-EPS and TB-EPS were similar, and the absorption peaks at $3500-3300 \mathrm{~cm}^{-1}, 1680-1630 \mathrm{~cm}^{-1}, 1630-1580 \mathrm{~cm}^{-1}, 1460-1350 \mathrm{~cm}^{-1}$, and $1000-1150 \mathrm{~cm}^{-1}$ were all apparent, which indicated that LB-EPS and TB-EPS in the activated sludge of the four reactors contained hydroxyl or amino groups, amide groups (protein peptide chain), polysaccharides or primary alcohols. The absorption peaks at $1330-1200 \mathrm{~cm}^{-1}$ of LB-EPS in the $35^{\circ} \mathrm{C}$ reactors were extremely weak, while those of TB-EPS were obvious, demonstrating that the carboxylic acid, phenol and polysaccharide groups in TB-EPS were more abundant than those in LB-EPS. Furthermore, the absorption peaks at $1680-1630 \mathrm{~cm}^{-1}$ of TB-EPS in the $35^{\circ} \mathrm{C}$ reactors were stronger than in TB-EPS, which indicated that the amide groups in TB-EPS were more plentiful than those in LB-EPS. 

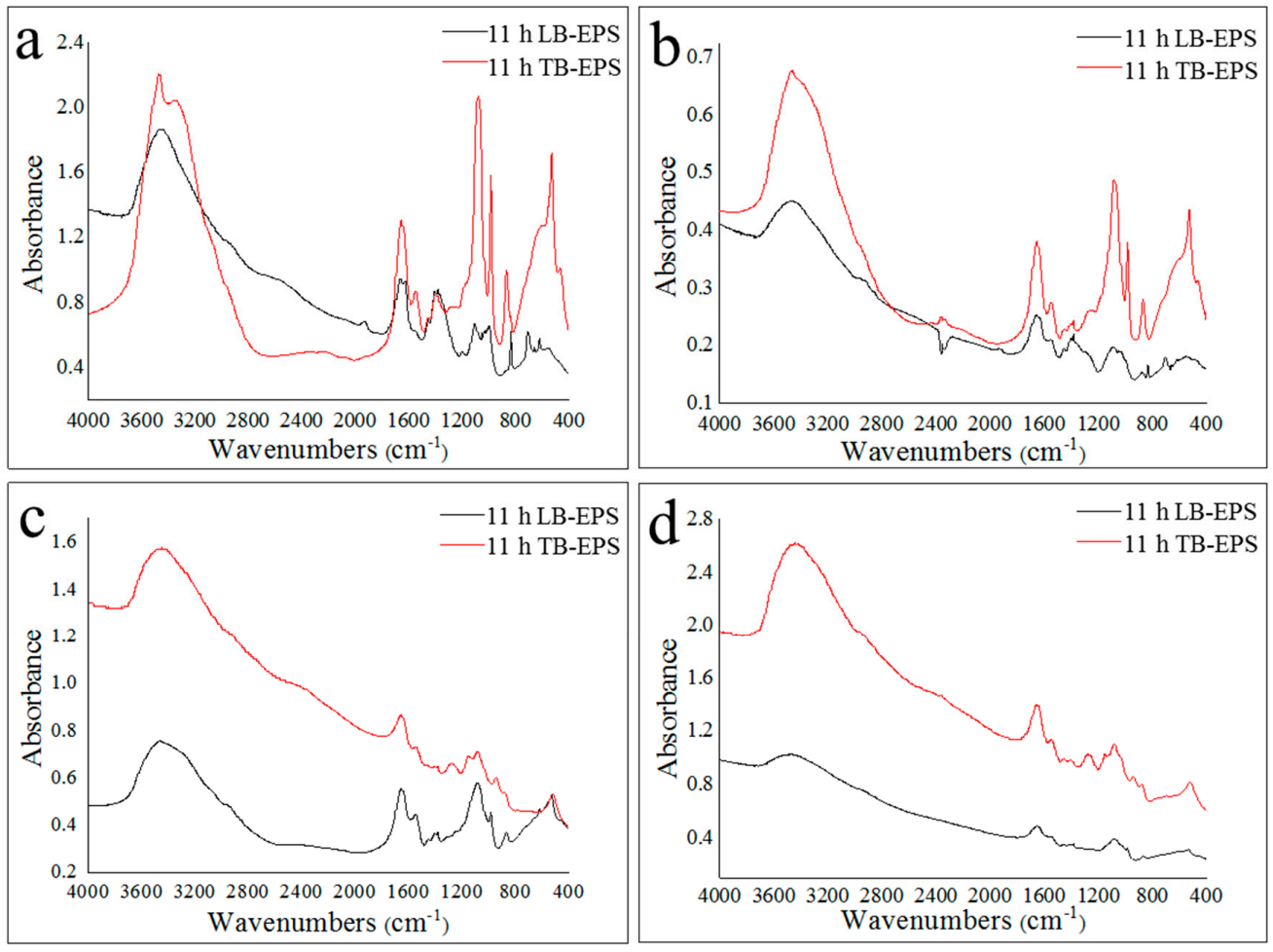

Figure 5. IR spectra of LB-EPS and TB-EPS at the later aerobic stage. (a): LB-EPS and TB-EPS from a $35{ }^{\circ} \mathrm{C}$ sodium acetate reactor; (b): LB-EPS and TB-EPS from a $35{ }^{\circ} \mathrm{C}$ sodium propionate reactor; (c): LB-EPS and TB-EPS from a $20{ }^{\circ} \mathrm{C}$ sodium acetate reactor; (d): LB-EPS and TB-EPS from a $20{ }^{\circ} \mathrm{C}$ sodium propionate reactor.

As shown in Figure 6, $\mathrm{TP}_{\mathrm{EPS}} / \mathrm{TOC}_{\mathrm{EPS}}$ of LB-EPS changed irregularly during the anaerobic-aerobic cycle, and $\mathrm{TP}_{\mathrm{EPS}} / \mathrm{TOC}_{\mathrm{EPS}}$ of LB-EPS in the activated sludge of the $20^{\circ} \mathrm{C}$ sodium acetate reactor was significantly higher than that of the other three reactors. Moreover, in the same activated sludge, the phosphorous adsorption/complexing performance of TB-EPS was significantly higher than that of LB-EPS. Specifically, the TP ${ }_{\mathrm{EPS}} / \mathrm{TOC}_{\mathrm{EPS}}$ of TB-EPS in activated sludge from the $35{ }^{\circ} \mathrm{C}$ sodium acetate reactor and sodium propionate reactor and from the $20^{\circ} \mathrm{C}$ sodium acetate reactor and sodium propionate reactor were 2.79-4.97, 1.56-2.63, 1.07-2.88 and 1.70-2.98 times higher than those of LB-EPS, respectively. The above phenomenon is mainly explained by two aspects. LB-EPS and TB-EPS were extracted via sonication and CER, respectively, and CER was more efficient at extracting phosphorus from EPS than sonication. Furthermore, the affinity for phosphate of TB-EPS was stronger than that of LB-EPS.
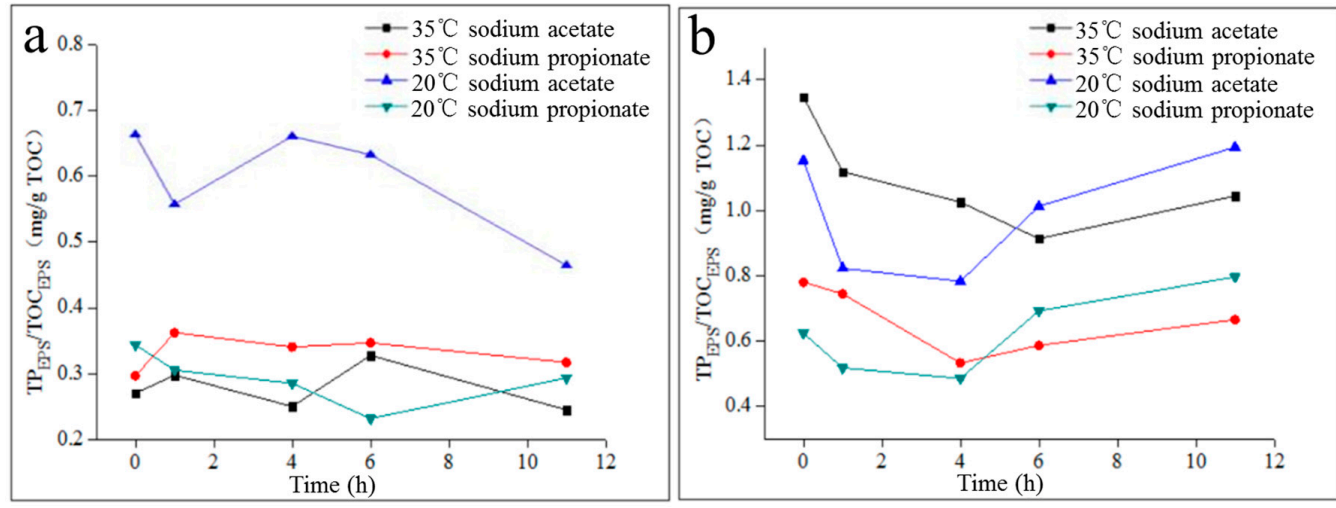

Figure 6. Performance of LB-EPS and TB-EPS phosphorous adsorption/complexing during the anaerobic-aerobic cycle. (a): LB-EPS; (b): TB-EPS. 


\subsection{The Effect of Metal Elements on TB-EPS Phosphorous Adsorption/Complexing}

As shown in Figure 7, the content of Ca in TB-EPS from activated sludge was much greater than that of other metals in the $35^{\circ} \mathrm{C}$ reactors, and the content of $\mathrm{K}, \mathrm{Mg}$ and $\mathrm{Ca}$ in TB-EPS from activated sludge in the $20^{\circ} \mathrm{C}$ reactors was greater than that of $\mathrm{Al}$ and $\mathrm{Fe}$. Fe in activated sludge mainly existed in microbial cells, while most Al was located in TB-EPS [26]. The main species of phosphorus (P) in the activated sludge of the $35^{\circ} \mathrm{C}$ reactors was orthophosphate (orthoP) [27] and a small number of orthoP combined with $\mathrm{K} / \mathrm{Mg}$ to form active metabolic complexes, while most orthoP combined with $\mathrm{Ca} / \mathrm{Al} / \mathrm{Fe}$ to form inert metabolic complexes. In addition, the $\mathrm{Ca} / \mathrm{Al}-\mathrm{P}$ complex mainly existed in TB-EPS, and the Ca/Fe-P complex was mainly located in microbial cells, both of which did not participate in the microbial metabolism process. The contents of $\mathrm{K}$ and $\mathrm{Mg}$ in TB-EPS from activated sludge were both below $0.5 \mathrm{mg} / \mathrm{g}$ TOC, the variation trends of which were not anaerobic-decreasing and aerobic-increasing during the anaerobic-aerobic cycle. TB-EPS in the activated sludge of the $35^{\circ} \mathrm{C}$ reactors directly released or took up orthoP, which played the role of the phosphorus $(\mathrm{P})$ transfer station. Therefore, a certain amount of phosphorus was maintained in the activated sludge of the $35^{\circ} \mathrm{C}$ reactors without biological phosphorus accumulation, and the EBPR performance was poor.
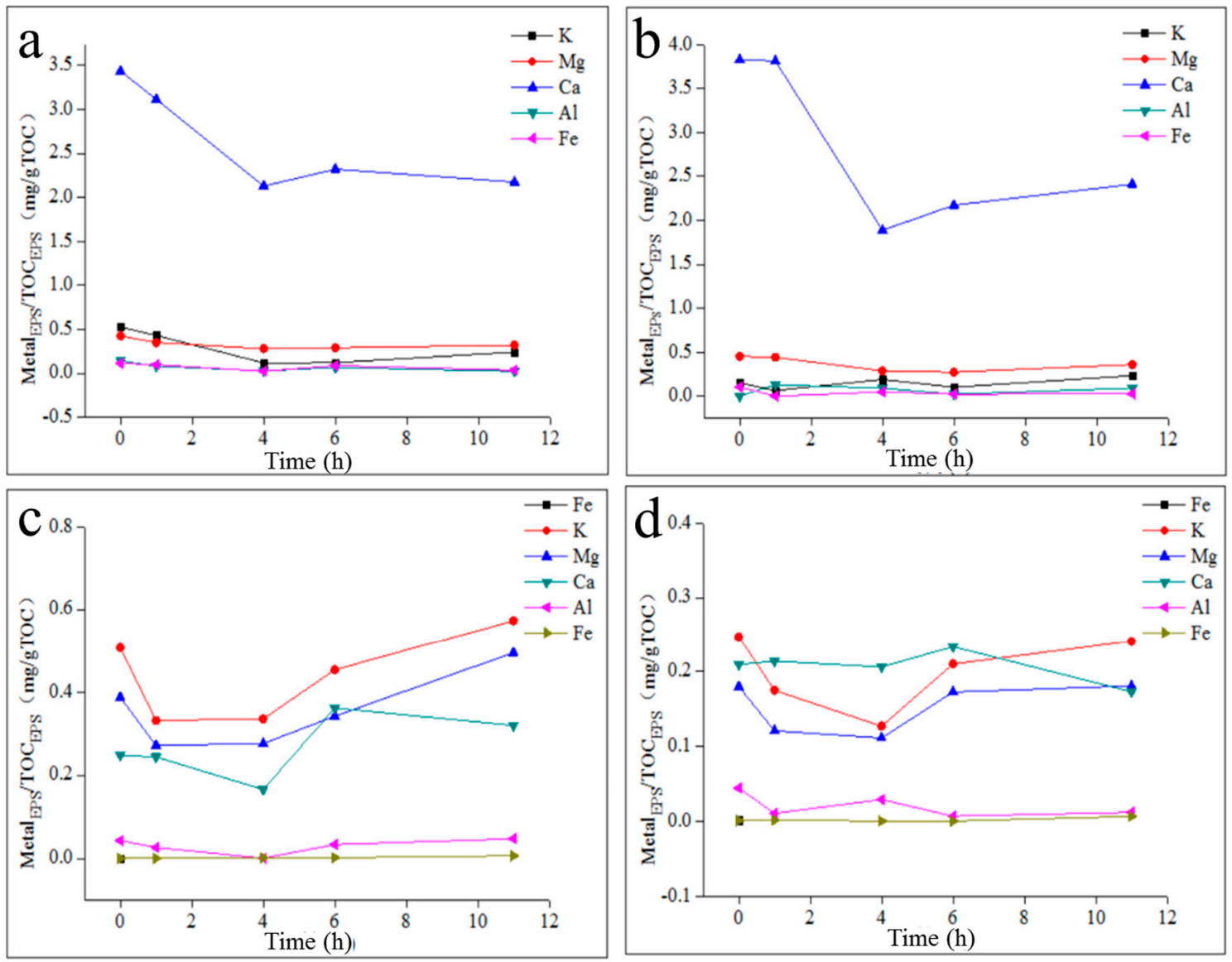

Figure 7. The content and variation of metal elements and TP in the TB-EPS during the anaerobic-aerobic cycle. (a): TB-EPS from a $35{ }^{\circ} \mathrm{C}$ sodium acetate reactor; (b): TB-EPS from a $35^{\circ} \mathrm{C}$ sodium propionate reactor; (c): TB-EPS from a $20{ }^{\circ} \mathrm{C}$ sodium acetate reactor; (d): TB-EPS from a $20{ }^{\circ} \mathrm{C}$ sodium propionate reactor. 
The main species of $\mathrm{P}$ in activated sludge from the $20^{\circ} \mathrm{C}$ reactors were orthoP and polyphosphate (polyP), and polyP was mainly located in TB-EPS [27]. Some P (including polyP and orthoP) in the activated sludge combined with $\mathrm{K}$ and $\mathrm{Mg}$ to form metabolic active complexes, such as $\mathrm{K} / \mathrm{Mg}$-polyP and $\mathrm{K} / \mathrm{Mg}$-orthoP, which could promote the migration and transformation of $\mathrm{P}$ in activated sludge. In addition, $\mathrm{K} / \mathrm{Mg}$-polyP mainly existed in TB-EPS, and $\mathrm{K} / \mathrm{Mg}$-orthoP was mainly located in microbial cells. Furthermore, the other portion of $\mathrm{P}$ (mainly orthoP) combined with $\mathrm{Ca} / \mathrm{Al} / \mathrm{Fe}$ to form inert metabolic complexes, in which Ca/Al-P complexes mainly existed in TB-EPS and Ca/Fe-P complexes were mainly located in microbial cells. Due to the high content of $\mathrm{K}$ and $\mathrm{Mg}$ in the activated sludge of the $20{ }^{\circ} \mathrm{C}$ reactors, a large amount of $\mathrm{P}$ combined with $\mathrm{K}$ and $\mathrm{Mg}$, and the main phosphorus species of TB-EPS were polyP. Moreover, the variation trends of $\mathrm{K}$ and $\mathrm{Mg}$ in TB-EPS from the activated sludge in the $20^{\circ} \mathrm{C}$ reactors were anaerobic-decreasing and aerobic-increasing, which indicated that TB-EPS participated in the biological phosphorus accumulation process. Therefore, the EBPR performance of activated sludge of the $20^{\circ} \mathrm{C}$ reactors was good.

\subsection{The Biochemical Reaction Process of TB-EPS Phosphate Adsorption/Complexing in EBPR-Activated Sludge}

As shown in Figure 8, the biochemical reaction process of TB-EPS phosphate adsorption/complexing in EBPR-activated sludge involved the migration and transformation between metal elements, polyP, proteins, and polysaccharides, which was closely related to anaerobic/aerobic metabolism. At the anaerobic stage (Figure 8a), the microbial cell decomposed intracellular energy substances (mainly intracellular glycogen) and released metabolic secretions into TB-EPS and LB-EPS. In addition, these metabolic secretions were mainly proteins and polysaccharides, in which the protein content was larger than that of polysaccharides. The microbial cells released intracellular K/Mg-orthoP into EPS and the bulk solution. Meanwhile, long-chain K/Mg-polyP in TB-EPS was decomposed into short-chain polyP and orthoP. The abovementioned orthoP accomplished anion exchange with VFAs in the bulk solution, which promoted the transfer of VFAs from the bulk solution into microbial cells to be synthesized into polyhydroxyalkanoates (PHA) with the energy produced by intracellular glycogen. In addition, the orthoP released by the microbial cell and produced by K/Mg-polyP decomposition in TB-EPS were transferred into the bulk solution, with the release of $\mathrm{K}^{+}$and $\mathrm{Mg}^{2+}$. The above results indicated that the microbial cell (mainly phosphorus-accumulating organisms, PAOs) obtained the competitive advantage of a carbon source.

At the aerobic stage (Figure $8 b$ ), taking $\mathrm{O}_{2}$ as the electron acceptor, PHA in the microbial cell decomposed, and intracellular glycogen was synthesized. Meanwhile, orthoP and metal ions in the bulk solution were absorbed and transferred into the microbial cell, using some of the proteins and polysaccharides in LB-EPS and TB-EPS as carbon sources. OrthoP and metal ions were transferred into TB-EPS after a short residence time in LB-EPS. Then, orthoP combined with metal ions, transforming into the inert $\mathrm{Ca} / \mathrm{Al}$-orthoP complex and the active $\mathrm{K} / \mathrm{Mg}$-orthoP complex in TB-EPS. Some of the $\mathrm{K} / \mathrm{Mg}$-orthoP was stored in TB-EPS, and the remainder was transferred into the microbial cell. Moreover, orthoP, which was transferred from the bulk solution and EPS into the microbial cell and combined with intracellular $\mathrm{K}, \mathrm{Mg}$, $\mathrm{Ca}$ and $\mathrm{Al}$, was transformed into the active $\mathrm{K} / \mathrm{Mg}$-orthoP complex and the inert $\mathrm{Ca} / \mathrm{Fe}$-orthoP complex. With the energy generated by PHA decomposition and with the consumption of intercepted $\mathrm{K} / \mathrm{Mg}$-orthoP, long-chain $\mathrm{K} / \mathrm{Mg}$-polyP was synthesized in TB-EPS. 

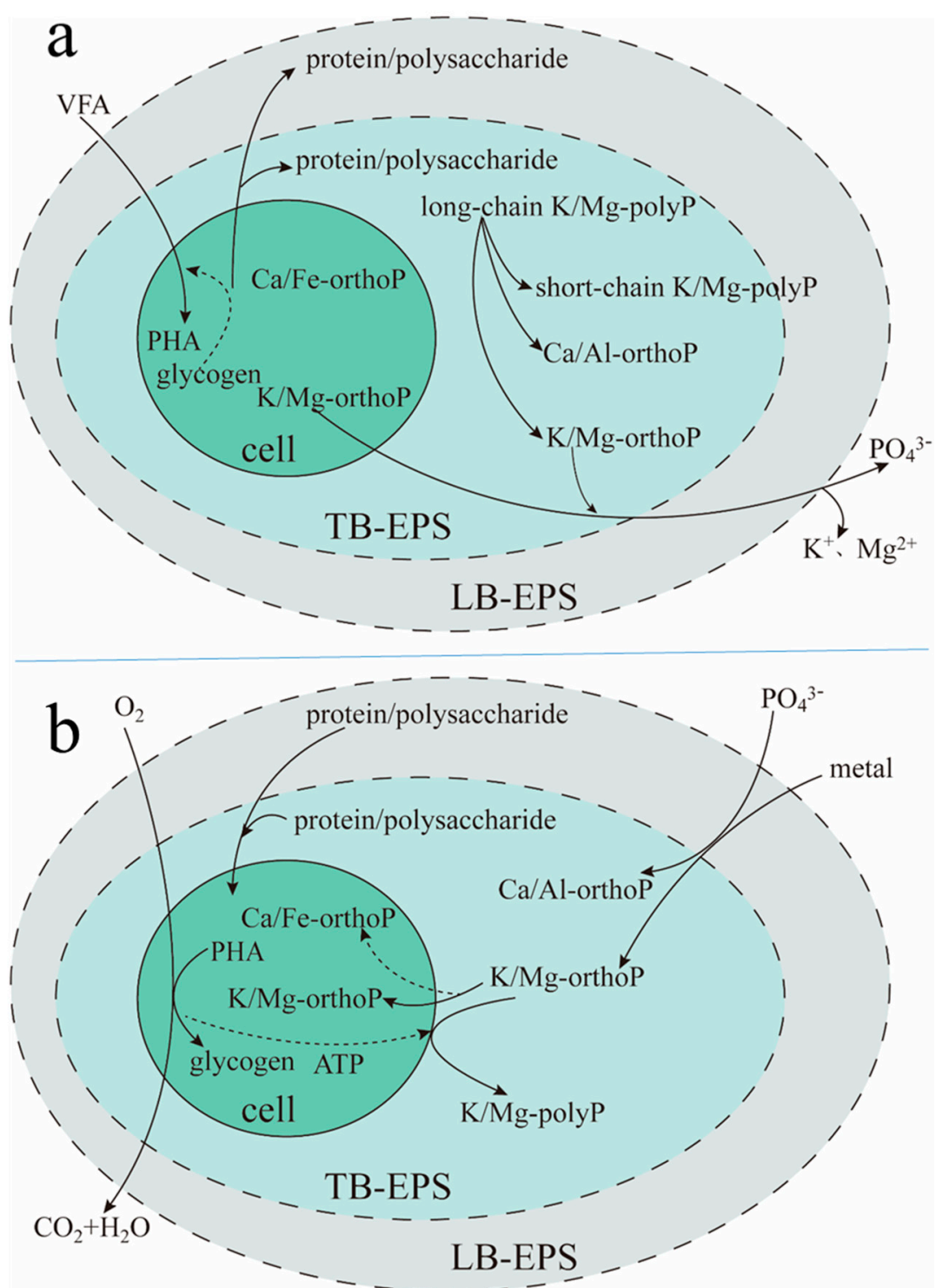

Figure 8. Supposed metabolic model for enhanced biological phosphorus removal (EBPR) with a consideration of the roles of TB-EPS and LB-EPS. (a): Anaerobic; (b): aerobic. Abbreviation: PHA: polyhydroxyalkanoates.

\section{Materials and Methods}

\subsection{Culture of Activated Sludge}

The activated sludge of four lab-scale A/O-SBR reactors was fed synthetic wastewater, adopting sodium acetate or sodium propionate as the sole carbon source. The chemical oxygen demand (COD): nitrogen $(\mathrm{N})$ : phosphorus $(\mathrm{P})$ ratio of the synthetic wastewater was 100:5:5, and the $\mathrm{pH}$ was approximately 7.0, and the trace elements are shown in Table S1. The reactors had a working volume of $15 \mathrm{~L}$ and were operated for 2 cycles every day, adopting instantaneous wastewater filling. Each cycle lasted for $12 \mathrm{~h}$, involving a 4-h anaerobic period, $7 \mathrm{~h}$ of aeration, a 50-min settlement time, $5 \mathrm{~min}$ of decanting, and $5 \mathrm{~min}$ of idling. The temperatures of the 4 reactors were controlled at $20 \pm 1{ }^{\circ} \mathrm{C}$ or $35 \pm 1{ }^{\circ} \mathrm{C}$. The solid retention times (SRTs) were approximately $20 \mathrm{~d}$, with discharging of the mixed liquid occurring every day. The dissolved oxygen (DO) concentrations under anaerobic conditions were $0.2-0.5 \mathrm{mg} / \mathrm{L}$, which would be directly related to the growth status, phosphorus release capacity, and the ability to synthesize an organic matrix of phosphorus-accumulating organisms 
(PAOs). Phosphorus uptake by microorganisms under aerobic conditions was much higher than that released under anaerobic conditions. Fine air bubbles for aeration were supplied through a dispenser at the bottom of the reactor with an airflow rate of $1.6 \mathrm{~L} / \mathrm{h}$, which ensured that the DO concentration at the end of the aeration stage was $3.0-5.0 \mathrm{mg} / \mathrm{L}$. The mixed liquid suspended solids (MLSS), sludge volume index (SVI) and the COD and TP of the effluent were monitored every day. After the values of the parameters remained relatively stable for 2 months, the experimental study was carried out.

\subsection{Method of Washing CER}

The $001 \times 7$ gel-type CER (16-40 mesh, Suqing, Jiangsu, China) was used for the CER extractions. The CER was washed successively with $8 \% \mathrm{NaCl}, 1 \mathrm{~mol} / \mathrm{L} \mathrm{HCl}$, and $1 \mathrm{~mol} / \mathrm{L} \mathrm{NaOH}$, alternating the $\mathrm{HCl}$ and $\mathrm{NaOH}$ solutions for 3 washes, washing to a neutral $\mathrm{pH}$ by pure water each time. At the end of the washing process, two successive alkaline washes were implemented, after which the CER was washed to a neutral $\mathrm{pH}$ for use.

\subsection{Extraction of EPS}

\subsubsection{Extraction of LB-EPS}

A modified sonication method was used to extract LB-EPS [4]. A sonicator operating at $21 \mathrm{kHz}$ (JY90-II; Scientz Bioscience Co., Inc., Ningbo, China) was used to extract $40 \mathrm{~mL}$ sludge (VSS was between $7500 \mathrm{mg} / \mathrm{L}$ and $8500 \mathrm{mg} / \mathrm{L}$ ) after centrifugation and resuspension. Subsequently, the treated sludge was centrifuged two times at $0 \pm 2{ }^{\circ} \mathrm{C}$ and $43,000 \mathrm{RCF}$, and the twice centrifuged supernatant was designated LB-EPS. The sonication probe area was $0.28 \mathrm{~cm}^{2}$, the ultrasonic power density was $1 \mathrm{~W} / \mathrm{mL}$, and the process time was $6 \mathrm{~min}$. The duty cycle during the sonication process was $50 \%$.

\subsubsection{Extraction of TB-EPS}

After extracting LB-EPS, the centrifuged pellet was resuspended in $40 \mathrm{~mL}$ water. Then, a modified CER method was used to extract TB-EPS [24]. The $001 \times 7$ gel-type CER (20-40 mesh, Suqing, Jiangsu, China) was employed to process the $40 \mathrm{~mL}$ mixed liquid samples. The amount of resin used was $100 \mathrm{~g}$ of CER/g VSS, and the reaction time was $30 \mathrm{~min}$. Then, the CER was filtered using nylon mesh with a 250-mm pore diameter. Finally, the filtered mixed liquid was centrifuged two times at $0 \pm 2{ }^{\circ} \mathrm{C}$ and 43,000 RCF, and the twice centrifuged supernatant was designated as TB-EPS.

\subsubsection{Extraction of EPS}

The washed sludge was processed by sonication and then reacted with the CER to perform cation exchange. Thereafter, the filtered mixed liquid was centrifuged twice at $0 \pm 2{ }^{\circ} \mathrm{C}$ and $43,000 \mathrm{RCF}$, and the supernatant was designated EPS.

\subsection{FTIR Analysis}

The functional groups constituting LB-EPS and TB-EPS extracted from sludge samples were well recognized by FTIR, which provides molecular information of bond angles and bonding patterns. The dried EPS was compressed to a $3 \mathrm{~mm}$ (diameter) disc using potassium bromide (KBr) and was recorded with a Bruker TENSOR 37 FTIR spectrophotometer at room temperature under inert conditions with a frequency range of 400 to $4000 \mathrm{~cm}^{-1}$ and at a resolution of $4 \mathrm{~cm}^{-1}$.

\subsection{Other Analyses}

The total organic carbon (TOC) of LB-EPS and TB-EPS extracts was detected using a TOC analyzer (multi N/C 2100 S, Analytik Jena AG, Jena, Germany). The DO concentration in mixed liquid was examined with a DO analyzer (Pro20, YSI, Columbus, Ohio, USA). The COD in effluent was detected using a COD instrument (DR1010, HACH, Loveland, Colorado, USA). The SVI, suspended solids (SS),

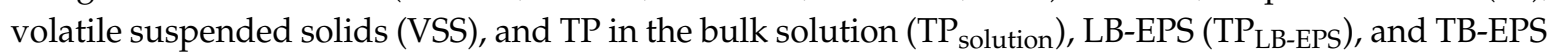


$\left(\mathrm{TP}_{\mathrm{TB}-\mathrm{EPS}}\right)$ were measured according to standard methods [28]. The TP in sludge (TP $\left.{ }_{\text {Sludge }}\right)$ was measured after resuspended sludge was dispersed by sonication, and the TP in microbial cells $\left(\mathrm{TP}_{\text {cell }}\right)$ was calculated by subtraction. The metal elements in the bulk solution, sludge, LB-EPS, and microbial cells were directly measured by ICP-OES (Agilent 715, Agilent Technologies Inc., Palo Alto, CA, USA). The metal elements in TB-EPS were calculated by subtraction. The morphology of microorganisms in the activated sludge was observed by a scanning electron microscope (MIRA 3 GMU/GMH; TESCAN, Brno, Czechoslovakia).

\section{Conclusions}

In this work, the adsorption performance of LB-EPS and TB-EPS for phosphate was explored, in which sonication and CER were used to extract LB-EPS and TB-EPS, respectively, from the activated sludge of four lab-scale A/O-SBR reactors with different temperatures and organic substrates. The results revealed that the content and functional groups of LB-EPS and TB-EPS in activated sludge are distinctly different. More concretely, the content of hydroxyl, amino, amide (protein peptide chain), polysaccharide, and primary alcohol groups in TB-EPS was much higher than that in LB-EPS. Moreover, the phosphate adsorption performance of TB-EPS was better than that of LB-EPS. More importantly, the supposed metabolic model for EBPR with consideration of the adsorption performance of LB-EPS and TB-EPS was proposed, and the migration and transformation of metal elements, phosphate, proteins, and polysaccharides during the anaerobic-aerobic cycle were analyzed.

Supplementary Materials: The following are available online, Table S1: The components of synthetic wastewater. Figure S1: Content of protein and polysaccharide in LB-EPS and TB-EPS during anaerobic-aerobic cycle. Figure S2: Component and content of PHA during anaerobic-aerobic cycle. Figure S3: Concentration of VFA in the supernatant during anaerobic-aerobic cycle.

Author Contributions: H.X. is responsible for the guidance and data analysis. D.L. is responsible for the extraction of EPS and measurements. This paper was written jointly by all the authors.

Funding: This work was supported by the National Natural Science Foundation of China (grant numbers 21577174, 21876204) and the Chinese Postdoctoral Science Foundation.

Acknowledgments: D.L. is grateful to the State Key Laboratory of NBC Protection for Civilian for helping to develop fundamental and essential academic competence. The authors are thankful to the National Natural Science Foundation of China for their financial support. We are thankful to the Institute of Chemistry Chinese Academy of Sciences for their great cooperation. We are thankful to, Xiujie Liu, for helping in manuscript editing.

Conflicts of Interest: The authors declare no conflict of interest.

\section{References}

1. Yan, L.L.; Yu, L.B.; Liu, Q.P.; Zhang, X.L.; Liu, Y.; Zhang, M.Y.; Liu, S.; Ren, Y.; Chen, Z.L. Effects of phosphorus on loosely bound and tightly bound extracellular polymer substances in aerobic granular sludge. Chem. Biochem. Eng. Q. 2019, 33, 59-68. [CrossRef]

2. Zhang, H.L.; Fang, W.; Wang, Y.P.; Sheng, G.P.; Zeng, R.J.; Li, W.W.; Yu, H.Q. Phosphorus removal in an enhanced biological phosphorus removal process: Roles of extracellular polymeric substances. Environ. Sci. Technol. 2013, 47, 11482-11489. [CrossRef] [PubMed]

3. Zhang, H.L.; Fang, W.; Wang, Y.P.; Sheng, G.P.; Xia, C.W.; Zeng, R.J.; Yu, H.Q. Species of phosphorus in the extracellular polymeric substances of EBPR sludge. Bioresource Technol. 2013, 142, 714-718. [CrossRef] [PubMed]

4. Han, X.; Wang, Z.; Zhu, C.; Wu, Z. Effect of ultrasonic power density on extracting loosely bound and tightly bound extracellular polymeric substances. Desalination 2013, 329, 35-40. [CrossRef]

5. Basuvaraj, M.; Fein, J.; Liss, S.N. Protein and polysaccharide content of tightly and loosely bound extracellular polymeric substances and the development of a granular activated sludge floc. Water Res. 2015, 82, $104-117$. [CrossRef] [PubMed]

6. Iorhemen, O.T.; Hamza, R.A.; Zaghloul, M.S.; Tay, J.H. Aerobic granular sludge membrane bioreactor (AGMBR): Extracellular polymeric substances (EPS) analysis. Water Res. 2019, 156, 305-314. [CrossRef] 
7. Zhao, W.; Yang, S.; Huang, Q.; Cai, P. Bacterial cell surface properties: Role of loosely bound extracellular polymeric substances (LB-EPS). Colloid Surf. B Biointerfaces 2015, 128, 600-607. [CrossRef] [PubMed]

8. Xiao, B.Y.; Luo, M.; Yang, T.; Guo, X.S.; Yi, H. Evaluation of the secondary structures of protein in the extracellular polymeric substances extracted from activated sludge by different methods. J. Environ. Sci. 2018, 6, 1663-1673. [CrossRef]

9. Sheng, G.P.; Yu, H.Q.; Li, X.Y. Extracellular polymeric substances (EPS) of microbial aggregates in biological wastewater treatment systems: A review. Biotechnol. Adv. 2010, 28, 882-894. [CrossRef]

10. Wang, B.B.; Liu, X.T.; Chen, J.M.; Peng, D.C.; He, F. Composition and functional group characterization of extracellular polymeric substances (EPS) in activated sludge: The impacts of polymerization degree of proteinaceous substrates. Water Res. 2017, 129, 133-142. [CrossRef]

11. Wang, H.; Deng, H.; Ma, L.; Ge, L. Influence of operating conditions on extracellular polymeric substances and surface properties of sludge flocs. Carbohyd. Polym. 2013, 92, 510-515. [CrossRef]

12. Güler, G.; Vorob'Ev, M.M.; Vogel, V.; Mäntele, W. Proteolytically-induced changes of secondary structural protein conformation of bovine serum albumin monitored by Fourier transform infrared (FT-IR) and UV-circular dichroism spectroscopy. Spectrochim. Acta A Mol. Biomol. Spectrosc. 2016, 161, 8-18. [CrossRef] [PubMed]

13. Song, Y.X.; Lu, C.H.; Liu, P.; Chai, X.L.; Chen, X.; Min, X.B.; Tang, C.J.; Chai, L.Y. Insights into the role of extracellular polymeric substances in $\mathrm{Zn}^{2+}$ adsorption in different biological sludge systems. Environ. Sci. Pollut. Res. 2018, 25, 36680-36692. [CrossRef] [PubMed]

14. Zhang, L.; Dong, D.; Hua, X.; Guo, Z. Inhibitory effects of extracellular polymeric substances on ofloxacin sorption by natural biofilms. Sci. Total Environ. 2017, 625, 178. [CrossRef] [PubMed]

15. Feng, L.J.; Wang, J.J.; Liu, S.C.; Sun, X.D.; Yuan, X.Z.; Wang, S.G. Role of extracellular polymeric substances in the acute inhibition of activated sludge by polystyrene nanoparticles. Environ. Pollut. 2018, 238, 859-865. [CrossRef] [PubMed]

16. Guo, G.; Wu, D.; Ekama, G.A.; Hao, T.; Mackey, H.R.; Chen, G. Denitrifying sulfur conversion-associated EBPR: Effects of temperature and carbon source on anaerobic metabolism and performance. Water Res. 2018, 141, 36-43. [CrossRef]

17. Oehmen, A.; Lemos, P.C.; Carvalho, G.; Yuan, Z.; Keller, J.; Blackall, L.L.; Reis, M.A.M. Advances in enhanced biological phosphorus removal: From micro to macro scale. Water Res. 2007, 41, 2271-2300. [CrossRef] [PubMed]

18. Qiu, G.; Zuniga-Montanez, R.; Law, Y.; Thi, S.S.; Nguyen, T.Q.N.; Eganathan, K.; Liu, X.; Nielsen, P.H.; Williams, R.B.H.; Wuertz, S. Polyphosphate-accumulating organisms in full-scale tropical wastewater treatment plants use diverse carbon sources. Water Res. 2019, 149, 496-510. [CrossRef]

19. Mielcarek, A.; Rodziewicz, J.; Janczukowicz, W.; Thornton, A. The feasibility of citric acid as external carbon source for biological phosphorus removal in a sequencing batch biofilm reactor (SBBR). Biochem. Eng. J. 2015, 93, 102-107. [CrossRef]

20. Shen, N.; Chen, Y.; Zhou, Y. Multi-cycle operation of Enhanced Biological Phosphorus Removal (EBPR) with different carbon sources under high temperature. Water Res. 2017, 114, 308-315. [CrossRef]

21. Kee, F.L.; Tadashi, S.; Ying, H.O.; Adeline, S.M.C.; Hak, K.Y.; Pei, Y. Kinetic and stoichiometric characterization for efficient enhanced biological phosphorus removal (EBPR) process at high temperatures. Bioproc. Biosyst. Eng. 2015, 38, 729-737.

22. Sayi-Ucar, N.; Sarioglu, M.; Insel, G.; Cokgor, E.U.; Orhon, D.; Loosdrecht, M.C.M.V. Long-term study on the impact of temperature on enhanced biological phosphorus and nitrogen removal in membrane bioreactor. Water Res. 2015, 84, 8-17. [CrossRef] [PubMed]

23. Zeng, F.; Jin, W.; Zhao, Q. Temperature effect on extracellular polymeric substances (EPS) and phosphorus accumulating organisms (PAOs) for phosphorus release of anaerobic sludge. RSC Adv. 2019, 9, 2162-2171. [CrossRef]

24. Frølund, B.; Palmgren, R.; Keiding, K.; Nielsen, P.H. Extraction of extracellular polymers from activated sludge using a cation exchange resin. Water Res. 1996, 30, 1749-1758. [CrossRef]

25. Wang, R.Y.; Li, Y.M.; Chen, W.L.; Zou, J.T.; Chen, Y.G. Phosphate release involving PAOs activity during anaerobic fermentation of EBPR sludge and the extension of ADM1. Chem. Eng. J. 2016, 287, 436-447. [CrossRef] 
26. Wang, R.D.; Peng, Y.Z.; Cheng, Z.L.; Ren, N.Q. Understanding the role of extracellular polymeric substances in an enhanced biological phosphorus removal granular sludge system. Bioresource Technol. 2014, 169, 307-312. [CrossRef] [PubMed]

27. Long, X.; Tang, R.; Fang, Z.; Xie, C.; Li, Y.; Xian, G. The roles of loosely-bound and tightly-bound extracellular polymer substances in enhanced biological phosphorus removal. Chemosphere. 2017, 189, 679-688. [CrossRef] [PubMed]

28. Clesceri, L.S.; Greenberg, A.E.; Eaton, A.D. Organic Contaminant. In Standard Methods for the Examination of Water and Wastewater, 20th ed.; APHA: Washington, DC, USA, 1999.

Sample Availability: Samples of the compounds are not available from the authors.

(C) 2019 by the authors. Licensee MDPI, Basel, Switzerland. This article is an open access article distributed under the terms and conditions of the Creative Commons Attribution (CC BY) license (http://creativecommons.org/licenses/by/4.0/). 